\title{
STRUCTURAL BEHAVIOUR OF REINFORCED CONCRETE SQUARE COLUMNS DAMAGED BY REBAR CORROSION
}

\author{
Usha Rani M. ${ }^{1}$, Subramanian K. ${ }^{2}$ \\ 'Department of Civil Engineering, St.Joseph College of Engineering and Technology, Dar es Salaam, Tanzania. \\ ${ }^{2}$ Department of Civil Engineering, Coimbatore Institute of Technology, Coimbatore, India \\ Email: ${ }^{1}$ murrajv2000@yahoo.com
}

\begin{abstract}
Reinforced cement concrete is one of the most versatile materials used in the construction industry worldwide. It is expected that the reinforced concrete structures will serve for a long period of time. But there are many instances of premature failure of R.C. structures raising doubts about its durability. Most of these failures are attributed to the corrosion of reinforcement embedded in concrete. Corrosion causes gradual deterioration of structures and consequently their expected service life drastically gets reduced. In some cases, sudden collapse of concrete structures due to corrosion have been reported. Agreat variety of concrete structures such as industrial structures, hydraulic structures, marine structures, storage tanks, sewage treatment plants, highway bridges, parking garages, buildings etc., experience the damaging effects of corrosion. Corrosion attack of concrete structures takes place whenever an aggressive medium is present. The low durability of corroding concrete structures has raised great concern because of the cost associated with replacing and maintaining the existing infrastructure and the potential hazard to the public if the problem is not corrected.
\end{abstract}

Key words: Steel Corrosion, Column, Axial behaviour, Energy absorption capacity, Weight Loss.

\section{INTRODUCTION}

Corrosion of steel embedded in concrete is a complex problem. Understanding the phenomenon is important. This understanding can only be gained by proper experimentation on concrete structural member. $\mathrm{RC}$ columns, the main structural member of RC structures, usually sustain axial forces of dead loads and live loads. When the structures are exposed to corrosive environment, premature failure of RC columns due to corrosion leads to ultimate collapse of the complete structure. Particularly, with the extensive use of de-icing salt in cold weather regions, key bridge components such as decks and piers are vulnerable to steel reinforcement corrosion. Design inadequacies and substandard detailing practices in the columns are often compounded by the effects of reinforcement corrosion owing to carbonation or chloride exposure in marine environment. W it $h$ t $h$ is background it is essential to study the influence of steel corrosion on the strength of an RC column in order to ensure its structural performance. In recent years, considerable research has been focused on the investigation on the behavior of beams, slabs in corrosive environment by using various protective coating and inhibitors by researchers. Relatively less work has been reported on RC columns subjected to steel corrosion. Hence the main objective of this research is to investigate the behavior of RC corroded columns under axial load.

\section{REVIEW OF LITERATURE}

Pantazopoulou et al (2001) discussed the structural behaviour of reinforced concrete columns with various reinforcement configuration subjected to accelerated corrosion condition in the laboratory. Fifty specimens of diameter $150 \mathrm{~mm}$ and $300 \mathrm{~mm}$ height were subjected to $6 \mathrm{~V}$ power supply in the accelerated corrosion process. It was concluded that the load carrying capacity and axial strain are reduced due to corrosion.

Tastani et al (2004) studied the structural behaviour of corrosion-damaged columns with sub-standard detailing of reinforcement comprising of 21 prismatic specimens. The specimens were subjected to $6 \mathrm{~V}$ power supply in the accelerated corrosion process for a period of 93 days. Their study concluded that the corroded columns reached lower strain at failure level and the lateral ties had undergone severe corrosion loss and were entirely ineffective in restraining elastic buckling and declines the axial load. Morris et al (2004) presented a study which was based on a correlation of electrochemical parameters such as corrosion potential and current density together with concrete resistivity and chloride concentration data. Cylindrical reinforced concrete test specimens were cast with four numbers of $10 \mathrm{~mm}$ diameter and exposed to sea shore and immersed in sea water. The performance of four different concrete mix proportioning was investigated over a period of 1000 days of exposure. Their study concluded that when the electrical resistivity of concrete increases from 2 to $100 \mathrm{~kW} \Omega \mathrm{cm}$ the value of chloride threshold increases from 0.44 to $2.32 \%$ relative to the weight of cement Ballim et al (2001) carried out experimental study on RC beams subjected to simultaneous load and steel corrosion. Reinforcement was accelerated by impressing a DC current on the main tension steel while the load was applied through a static spring-loaded support frame. Their study concluded that depending on the extent of 
corrosion on the mode of failure, the ultimate bending strength of the beams reduces up to $30 \%$.

In most of the previous studies, attempts have been made by different authors on corrosion study on reinforced concrete beams and slabs by using various protective coating to steel, inhibitors, service life prediction model, Non- destructive tests to study the electrochemical behaviour, and corrosion monitoring methods, and relatively less work has been reported on $\mathrm{RC}$ columns subjected to steel corrosion. Hence, there is a lot of scope for studying the effect of corrosion on the strength and ductility of reinforced concrete columns.

\section{EXPERIMENTAL PROGRAMME}

\section{A. Materials Used and their Properties}

Ordinary Portland cement (OPC) 53 grade confirming to IS 12269(1987) obtained from a single source having a specific gravity of 3.15 was used in this study. Locally available river sand which falls in zone III of IS $383-1970$, and with a specific gravity of 2.55 , fineness modulus of 2.73 were used as fine aggregate. The crushed blue granite having a specific gravity of 2.69 were used as coarse aggregate.

\section{B. Mix Proportions}

The concrete mix was proportioned to target a mean strength of $30 \mathrm{Mpa}$. The procedure for proportioning of ingredients for the mix was based on Indian standards IS: 10262-1982. A mix proportion was arrived at to target the above strength. To find the workability of fresh concrete, concrete sample were taken from various batches of mixed concrete and tested in slump cone apparatus. It gave satisfactory slump values ranging from $80 \mathrm{~mm}$ to 150 $\mathrm{mm}$. The design mix proportion is furnished in Table 1.

Table 1. Mix Proportions of the Concrete

\begin{tabular}{|l|c|l|}
\hline \multicolumn{1}{|c|}{ Ingredient } & $\mathrm{kg} / \mathrm{m}^{3}$ & Proportion \\
\cline { 1 - 2 } Portland Cement & 450 & \multirow{2}{1}{ 1: $1.12: 2.687$} \\
\cline { 1 - 2 } Water & 191.6 & W/ C $=0.425$ \\
\cline { 1 - 2 } Fine Aggregate & 504 & \\
\cline { 1 - 2 } Coarse Aggregate & 1209 & \\
\hline
\end{tabular}

\section{Details of Test Specimen}

Totally forty eight columns were cast, three specimens for each Size. The columns were reinforced with 4 Nos of $10 \mathrm{~mm}$ diameter as main reinforcement and lateral ties of $6 \mathrm{~mm}$ diameter was used. The specimen names composed of three terms is shown in Table 2.
Table 2. Details of Test Specimen - Square Column

\begin{tabular}{|c|c|c|c|c|c|}
\hline Specimen & $\begin{array}{c}\text { No } \\
\text { of Specimen }\end{array}$ & $\begin{array}{l}\text { Size of the } \\
\text { Column }\end{array}$ & $\begin{array}{l}\text { Cover } \\
\text { in } \mathrm{mm}\end{array}$ & $\begin{array}{c}\text { Main } \\
\text { Reinforcement }\end{array}$ & $\begin{array}{c}\text { Lateral } \\
\text { Ties }\end{array}$ \\
\hline S1UC & 3 & \multirow{2}{*}{$\begin{array}{c}150 \times 150 \times \\
500 \mathrm{~mm} \\
\text { Height }\end{array}$} & \multirow{2}{*}{25} & \multirow{2}{*}{$\begin{array}{l}4 \text { Nos }-10 \mathrm{~mm} \\
\text { diameter }\end{array}$} & \multirow{2}{*}{$\begin{array}{l}6 \mathrm{~mm} \text { dia at } \\
150 \mathrm{~mm} \mathrm{c} / \mathrm{c}\end{array}$} \\
\hline $\mathrm{S} 1 \mathrm{C}$ & 3 & & & & \\
\hline S2UC & 3 & \multirow{4}{*}{$\begin{array}{c}125 \times 125 \times \\
500 \mathrm{~mm} \\
\text { Height }\end{array}$} & \multirow{4}{*}{20} & \multirow{4}{*}{$\begin{array}{l}4 \text { Nos }-10 \mathrm{~mm} \\
\text { diameter }\end{array}$} & \multirow{4}{*}{$\begin{array}{l}6 \mathrm{~mm} \text { dia at } \\
125 \mathrm{~mm} \mathrm{c} / \mathrm{c}\end{array}$} \\
\hline $\mathrm{S} 2 \mathrm{C}$ & 3 & & & & \\
\hline S2LUC & 3 & & & & \\
\hline S2LC & 3 & & & & \\
\hline S3uc & 3 & \multirow{4}{*}{$\begin{array}{c}125 \times 125 \times \\
1000 \mathrm{~mm} \\
\text { Height }\end{array}$} & \multirow{4}{*}{20} & \multirow{4}{*}{$\begin{array}{c}4 \text { Nos }-10 \mathrm{~mm} \\
\text { diameter }\end{array}$} & \multirow{4}{*}{$\begin{array}{l}6 \mathrm{~mm} \text { dia at } \\
125 \mathrm{~mm} \mathrm{c} / \mathrm{c}\end{array}$} \\
\hline $\mathrm{S} 3 \mathrm{C}$ & 3 & & & & \\
\hline S3LUC & 3 & & & & \\
\hline S3LC & 3 & & & & \\
\hline$S 4 U C$ & 3 & \multirow{2}{*}{$\begin{array}{c}150 \times 150 \times \\
2000 \\
\text { Height }\end{array}$} & \multirow{2}{*}{25} & \multirow{2}{*}{$\begin{array}{c}4 \text { Nos }-10 \mathrm{~mm} \\
\text { diameter }\end{array}$} & \multirow{2}{*}{$\begin{array}{l}6 \mathrm{~mm} \text { dia at } \\
150 \mathrm{~mm} \mathrm{c} / \mathrm{c}\end{array}$} \\
\hline $\mathrm{SAC}$ & 3 & & & & \\
\hline S5LUC & 3 & \multirow{4}{*}{$\begin{array}{c}150 \mathrm{~mm} \text { dia } \times \\
300 \mathrm{~mm} \text { Height }\end{array}$} & \multirow{4}{*}{20} & \multirow{4}{*}{$\begin{array}{l}4 \text { Nos }-10 \mathrm{~mm} \\
\text { diameter }\end{array}$} & \multirow{4}{*}{$\begin{array}{c}6 \mathrm{~mm} \text { dia at } 73 \\
\mathrm{~mm} \mathrm{c} / \mathrm{c}\end{array}$} \\
\hline S5LC & 3 & & & & \\
\hline S5UC & 3 & & & & \\
\hline $\mathrm{S} 5 \mathrm{C}$ & 3 & & & & \\
\hline
\end{tabular}

The first term refers to the first size referred as S1. The second term "UC" as uncorroded specimens and " $\mathrm{C}$ " as Corroded specimen. The third term "L" refers to Loading condition of corrosion process. The columns S3UC had a middle test region $750 \mathrm{~mm}$ long and two enlarged capitals at their ends. The capital of height 125 $\mathrm{mm}$ was provided at both ends of the column to distribute the load evenly. To facilitate connection to the power supply and half cell measurement, small hole of $3 \mathrm{~mm}$ diameter was drilled in the longitudinal reinforcement. Through this hole insulated electrical wire was soldered. In order to prevent the connection from the ill effects of chloride the soldered portion was covered thoroughly with sealing compound. The wire was held in place so that it exited from the top face of the column.

\section{Method of Accelerating Reinforcement Corrosion}

Galvanostatic method was to accelerate the corrosion of the reinforcement. This method involved connecting the positive terminal of a DC power supply to the main reinforcement thus forcing it to become anodic. The negative electrode was then connected to a stainless steel plate placed in the electrolytic solution and the cathodic/anode surface area ratio of 3.7 were adopted. The scale model columns were placed in fibre reinforced plastic tank were subjected to a current of 5V.Two third portions of the columns were immersed in $3 \% \mathrm{NaCl}$ solution. Fig. 1 shows the accelerated corrosion process of the specimen. 


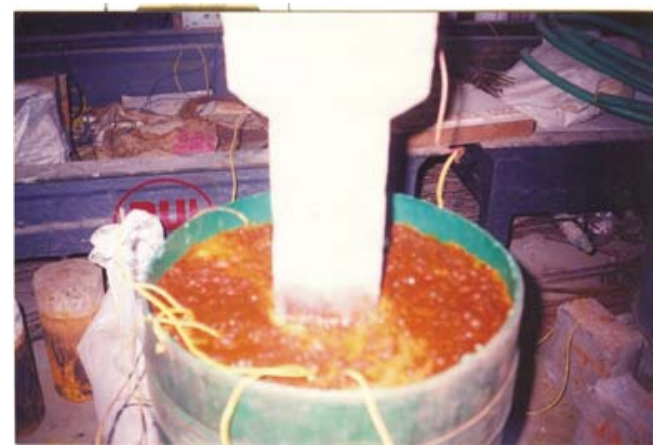

Fig. 1. Accelerated Corrosion Process

\section{E.Sustained Load Corrosion Process}

A load of $45 \mathrm{kN}$ was applied to the specimens. The loading was exerted by keeping two $2.5 \mathrm{~cm}$ thick steel plates one at the top and the other at the bottom of the specimens and the whole assembly is tightened with threaded rod and nuts which was controlled by a torque wrench. The load decreases as the corrosion proceeds (Creep effects) with increase in time. To maintain the loads constant throughout the duration of the test, continuous monitoring and adjustment of nuts were required. The steel plates, nuts and bolts were plated with Zinc coating to avoid the galvanostatic corrosion.

\section{F. Instrumentation and Testing Procedure}

All specimens were loaded until failure under axial compression in a testing frame. The top of the column specimens were provided with a steel box of column size to ensure uniform distribution of the load on the specimen. Longitudinal strains were manually using DEMEC gauge with $150 \mathrm{~mm}$ lengths having a least count of $0.002 \mathrm{~mm}$. Pellets were glued either on the concrete surface. Pellets were fixed at mid height of the column for strain measurements in the longitudinal direction. Strains were noted down for every $100 \mathrm{kN}$ increment of load. Test set up for the columns is shown in Fig. 2 and 3.

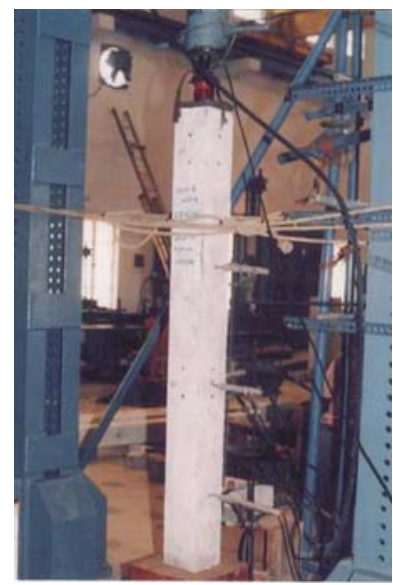

Fig. 2. Test Set - up - of Column S4UC

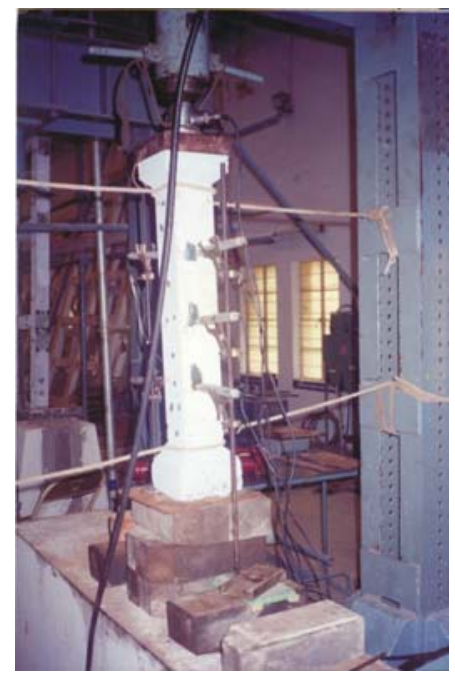

Fig. 3. Test Set - up - of Column S3UC

\section{RESULTS AND DISCUSSION}

The corrosion activity of column specimens are evaluated by destructive tests. In the Destructive test the effect of corrosion on ultimate load, axial strain, energy absorption capacity and weight loss of steel of all the specimens were studied.

\section{A. Effect of Corrosion on Axial Behaviour}

The effect of corrosion on the axial load carrying capacity, energy absorption capacity, and ductility of reinforced columns are examined and discussed in detail in the following section. The comparisons are presented in Fig. 4 to 6. All the specimens were tested under monotonic loading. The first set includes S1UC, S1C, S1UC served as control columns. All the corroded specimens were subjected to thirty days of corrosion. The control specimen failed due to shear and this failure was indicated by inclined cracks appearing on the sides of the column.

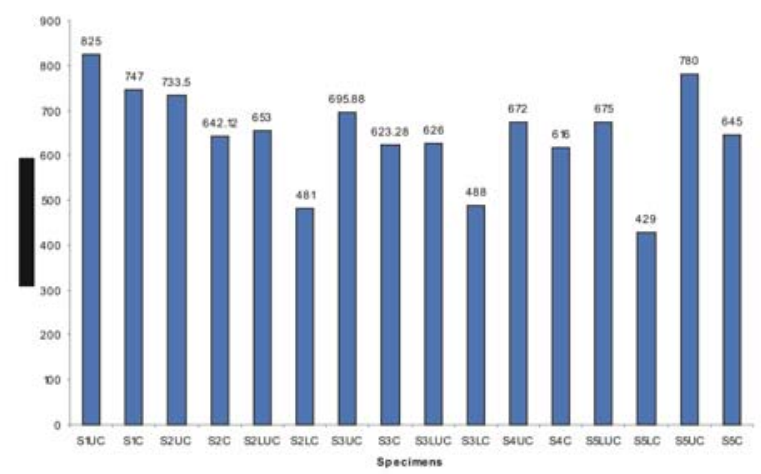

Fig. 4. Comparison of ultimate load between corroded and uncorroded column - S series specimens 
Usha Rani et al : Structural Behaviour of Reinforced Concrete quare...

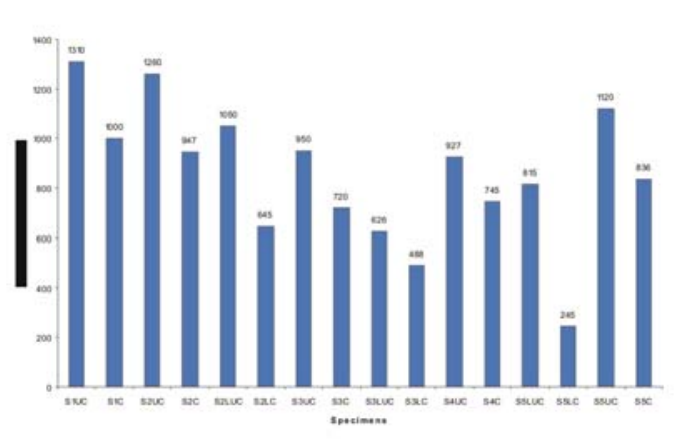

Fig. 5. Comparison of axial strain between corroded and uncorroded column - $\mathrm{S}$ series specimens

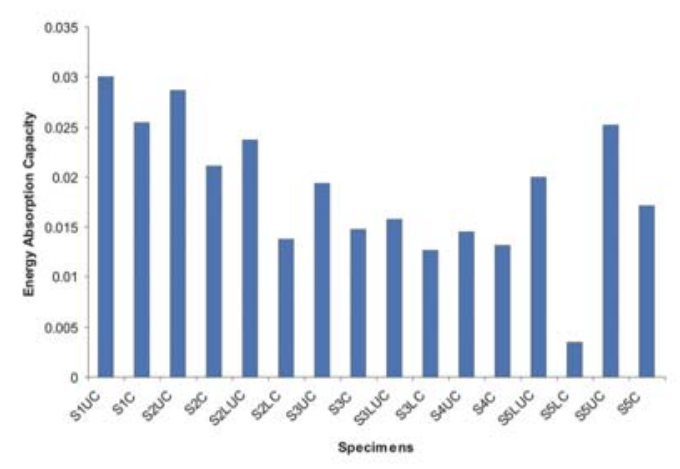

Fig. 6. Comparison of energy absorption capacity between corroded and uncorroded column - S series specimens

The specimen attained the peak load of $825 \mathrm{kN}$. The axial stains were measured at eighty percentage of loading and energy absorption capacity was calculated for the area under the stress-strain curve. Specimen S1C reached an ultimate load of $747 \mathrm{kN}$ which is $10 \%$ less than SIUC. This can be ascribed to the deterioration of the bond at the steel to concrete interface caused by corrosion and reduction in the cross sectional area of the reinforcing bars. This is supported by the observation of a strain in about $1000 \mu €$ (micro strain) which is $24 \%$ less than the virgin specimens. The energy absorption capacity is reduced by $15 \%$.

The second set specimens includes S2UC, S2C, S2LUC and S2LC. S2UC attained the maximum load of $734 \mathrm{kN}$ followed in sequence by S2LUC, S2C and S2LC. Specimen S2C reached an ultimate strength of $642 \mathrm{kN}$, which is 1.14 times less than the conventional column. The axial strain decreases by a factor of 1.33 and energy absorption decreases by 1.36 times than the uncorroded column. The ultimate load observed in the specimen S2LUC was $653 \mathrm{kN}$. which is 1.12 times less than the conventional specimen. The axial stain and energy absorption are observed as 1.2 times less than S2UC.

Specimen S2LC attained an ultimate load of $481 \mathrm{kN}$ which is $25 \%$ less than that of S2C and $27 \%$ less than S2LUC. The axial strain in S2LC decreases by $39 \%$ when compared to S2LUC and 32\% when compared to S2C. At the same time $42 \%$ and $35 \%$ variations were observed in the energy absorption capacity. Sustained load expedited the initiation of reinforcement corrosion in the specimens by cracks in the concrete. These cracks might connect flow paths facilitating water and ion penetration to the surface of reinforcing steel and further accelerate the corrosion of reinforcement. Once the corrosion progresses, it leads to further surface cracking, delamination and debonding, resulting in reduction of the ultimate capacity and axial rigidity.

The third set of specimens include S3UC, S3C, S3LUC and S3LC. Specimen S3C sustains an ultimate strength of $623 \mathrm{kN}$, which is $11 \%$ less than the estimated virgin strength of $696 \mathrm{kN}$. The axial strain and energy absorption capacity decreases by $24 \%$ than the conventional specimen. The ultimate load taken by the specimen S3LUC was $626 \mathrm{kN}$, which is $10 \%$ less than the conventional specimen. The axial stain and energy absorption are observed as $14 \%$ and $18 \%$ less than S3UC. Specimen S3LC attained an ultimate load of 488 $\mathrm{kN}$ which is $22 \%$ less than that of S3C and S3LUC. Notable percentage variation was observed in axial strain. The value of $27 \%$ was noted when compared to S3LUC and $17 \%$ when compared to S2C. At the same time $20 \%$ and $14 \%$ variations were observed in the energy absorption capacity.

Specimen S4C reached an ultimate load of $616 \mathrm{kN}$ which is $8 \%$ less than the S4UC. The observation of strain is about $745 \mu €$ (micro strain) which is $20 \%$ less than the virgin specimens. The energy absorption capacity is reduced to $9 \%$ when compared to S4UC. The control column failed due to buckling and this failure was indicated by a lump of concrete spalling from the sides of the column at approximately mid height at the ultimate load level. The specimen attained the peak load of 672 kN.Specimen S5LC reached an ultimate load of $429 \mathrm{kN}$ which is $36 \%$ less than the S45LUC. The observation of strain is about $245 \mu €$ (micro strain) which is $70 \%$ less than the virgin specimens. The energy absorption capacity is reduced to $83 \%$ when compared to S5LUC.

\section{B. Stress-Strain Response}

Typical Stress- Strain curves for uncorroded and corroded specimens are shown in Fig. 7 to 9. Each curve is an average of the stress-strain curves for the three identical specimens with the same level of corrosion. The axial rigidity of the column decreases due to corrosion. The above behaviour can be related to the development of cracks which may affect the failure mode and ultimate strength of the specimen through the significant loss of bond between concrete and reinforcement. 


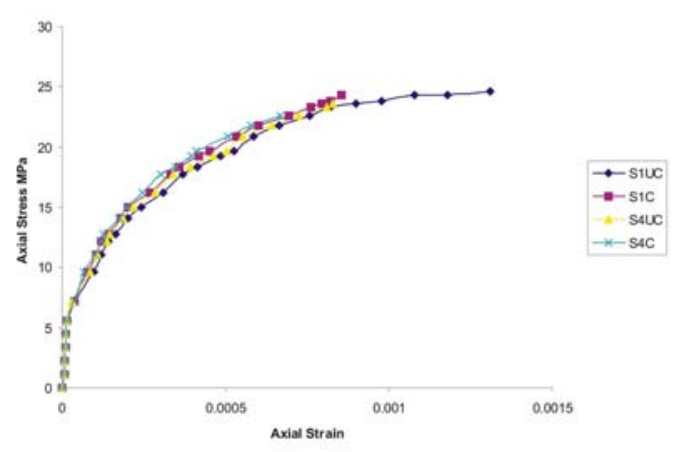

Fig. 7. Axial stress Vs axial strain for S1 and S4 series specimens

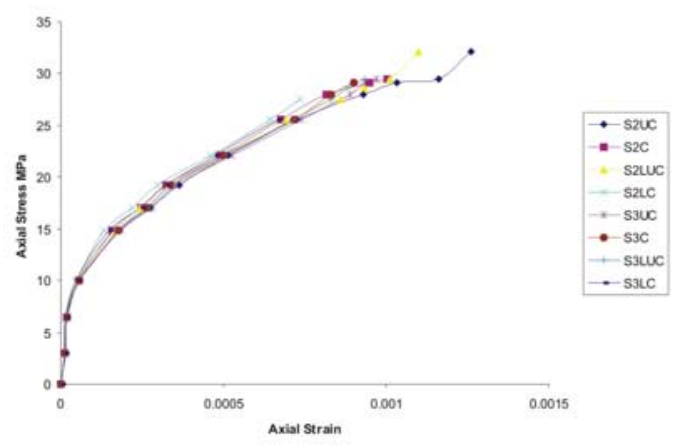

Fig. 8. Axial stress Vs axial strain for $\mathrm{S} 2$ and $\mathrm{S} 3$ series specimens

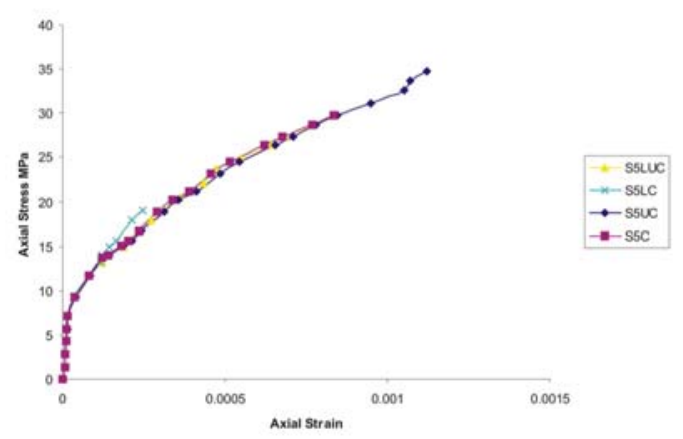

Fig. 9. Axial stress Vs axial strain for S5 series specimen

\section{Failure Mode of Square Column}

In corroded column, the failure started in the lower corroded portion and extended over the entire specimen and disintegration of the concrete cover and core especially in the lower half of the columns. The spalling of concrete cover was caused due to corrosion cracks and it occurs all over the length. This premature mode of failure was accompanied by simultaneous buckling of longitudinal reinforcement. In the case of convention column, the fine irregular cracks were noticed in the surface of the columns. These cracks get widened with increase in load level and the concrete was crushed as the longitudinal reinforcement had yielded. Fig. 10 to 15 show the failure mode.

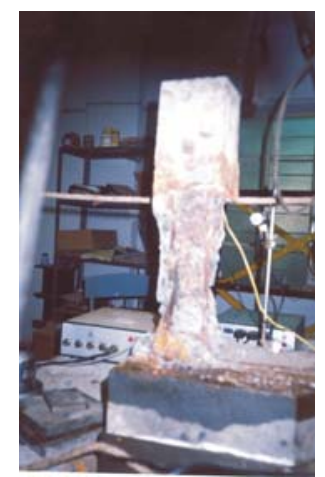

Fig. 10. Failure Mode of S2C Specimen

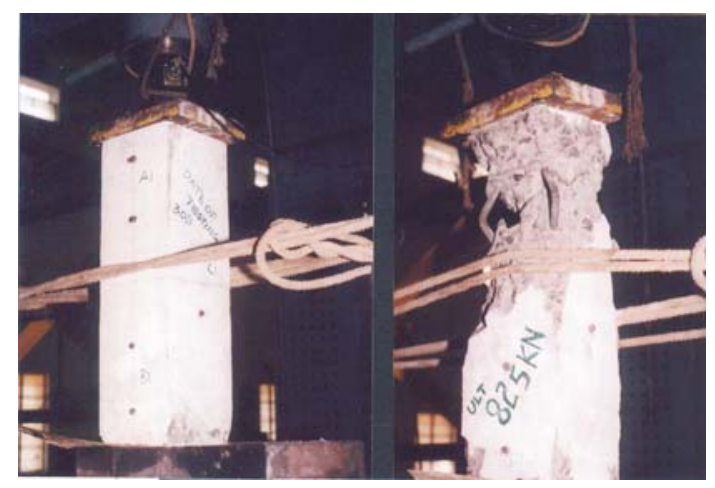

Fig. 11. Failure Mode of S1UC Specimen

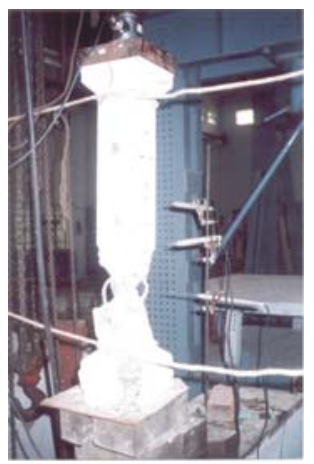

Fig. 12. Failure Mode of S3C Specimen

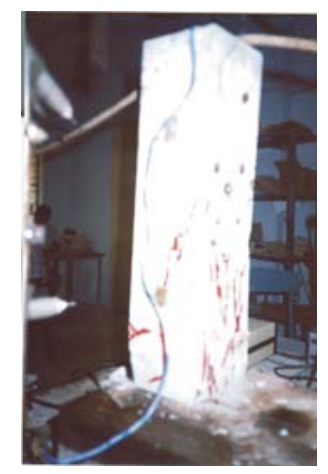

Fig. 13. Failure Mode of S2UC Specimen 


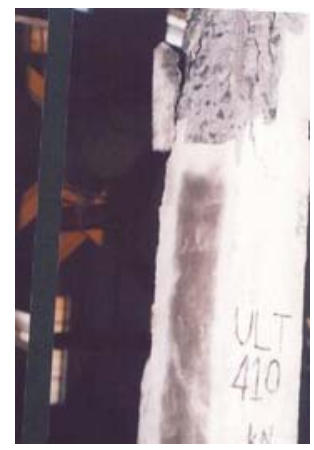

Fig. 14. Failure Mode of S4C Specimen

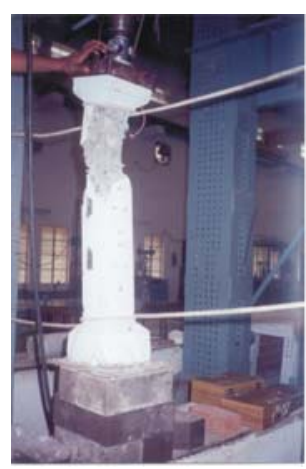

Fig. 15. Failure Mode of S3UC Specimen

\section{Measurement of Weight Loss}

The loss of weight of the rebars were calculated by the gravimetric method. Fig. 16 shows the percentage weight loss of the $S$ series specimens. Fig. 17 shows the corroded rebars.

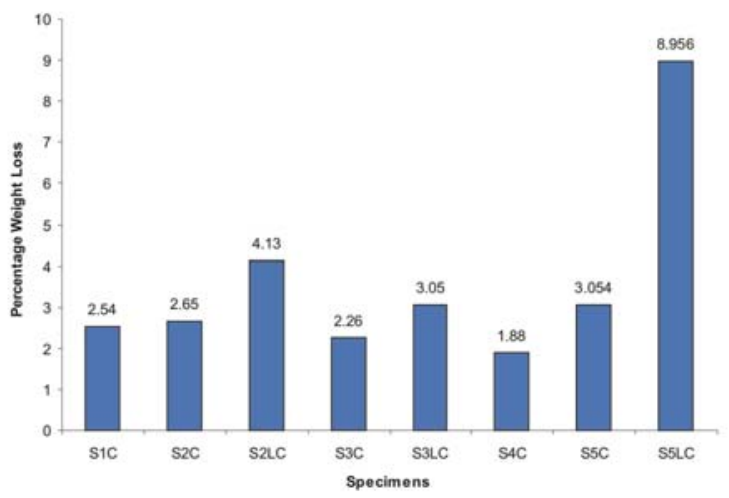

Fig. 16. Comparison of weight loss - S Series Specimens

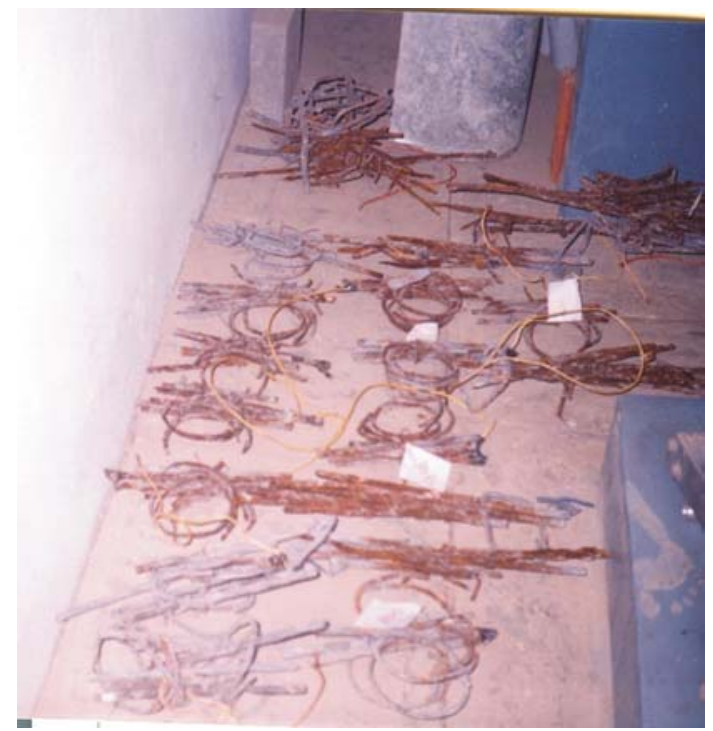

Fig. 17. Corroded rebars

\section{CONCLUSION}

The following conclusions are arrived at based on this study:

w The load carrying capacity, ductility and energy absorption capacity of the conventional column increases with the increase in the cross section of the column (S1UC and S2UC).

w The load carrying capacity, ductility and energy absorption capacity of the conventional short (S1UC) column increases with respect to long column (S4UC) of same cross section.

w The percentage decrease in load carrying capacity, ductility and energy absorption capacity of the corroded column decreases with the increase in the cover concrete (S1C and S2C).

w The percentage decrease in load carrying capacity, ductility and energy absorption capacity of the corroded short column increases when compared to the percentage decrease in long column of the same cover (S1C and S4C).

w The percentage loss of weight in steel increases with decrease in cover and the percentage decrease in load carrying capacity of the corroded column increases with increase in percentage weight loss of steel.

w The percentage loss of weight in steel and load carrying capacity of the corroded column increases with decrease in surface areas of steel embedded.

The sustained load and accelerated corrosion procedure 


\section{REFERENCES}

[1] ASTM G1-67 (1971), 'Recommended Practice for Preparing Cleaning and Evaluating Corrosion Test Specimens', American Society for Testing and Materials, Pennsylvania.

[2] Ballim Y., Reid J.C. and Kemp A.R. (2001), 'Deflection of RC Beams under Simultaneous Load and Steel Corrosion', Magazine of Concrete Research, Vol.53, No.3, pp.171-181.

[3] IS: 383-1970, 'Specifications for Coarse and Fine Aggregates from Natural Sources for Concrete', Bureau of Indian Standards, New Delhi.

[4] IS: 2386-1963, Part III, 'Indian Standard Methods of Test for Aggregates for Concrete', Bureau of Indian Standards, New Delhi.

[5] IS: 456-2000, 'Plain and Reinforced Concrete Code of Practice', Bureau of Indian Standards, New Delhi.

[6] IS: 516-1959, 'Methods of Tests for Strength of Concrete', Bureau of Indian Standards, New Delhi.

[7] IS: 10262-1982, 'Recommended Guideline for Concrete Mix Design', Bureau of Indian Standards, New Delhi.

[8] IS: 12269-1987, 'Specifications for 53 Grade Ordinary Portland Cement, Bureau of Indian Standards, New Delhi.
[9] Morris W., Vico A. and Vazquez M., (2004), 'Chloride Induced Corrosion of Reinforcing Steel Evaluated by Concrete Resistivity Measurements' Electrochimica Acta, Vol.49, No. 25, pp. 4447-4453.

[10] Pantazopoulou S.J., Bonacci J.F., Sheikh S., Thomas M.D.A. and Hearn N., (2001), 'Repair of Corrosion - Damaged Columns with FRP Wraps', Journal of Composites for Construction, Vol.5, No.1, pp.3-11.

[11] Tastani S.P. and Pantazopoulou S.J. (2004), 'Experimental Evaluation of FRP Jackets in Upgrading RC Corroded Columns with Substandard Detailing', Engineering Structures, Vol.26, No. 6, pp.817-829.

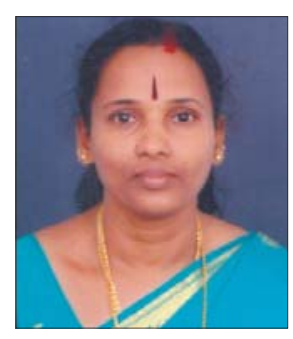

Ms. M. Usha Rani is a lecturer in the Department of Civil Engineering at St.Joseph College of Engineering and Technology, Dar es Salaam,Tanzania and submitted her Ph.D Thesis to Anna University - Chennai. She is a postgraduate from Coimbatore Institute of Technology, Tamilnadu. 